\title{
Gap Junction-Dependent Homolog Avoidance in the Developing CNS
}

\author{
Michael W. Baker, Neema Yazdani, and Eduardo R. Macagno \\ Section of Cell and Developmental Biology, University of California, San Diego, La Jolla, California 92093
}

Oppositely directed projections of some homologous neurons in the developing CNS of the medicinal leech (Hirudo verbana), such as the AP cells, undergo a form of contact-dependent homolog avoidance. Embryonic APs extend axons within the connective nerve toward adjacent ganglia, in which they meet and form gap junctions (GJs) with the oppositely directed axons of their segmental homologs, stop growing, and are later permanently retracted (Wolszon et al., 1994a,b). However, early deletion of an AP neuron leads to resumed growth and permanent maintenance of the projections of neighboring APs. Here we test the hypothesis that a GJ-based signaling mechanism is responsible for this instance of homolog avoidance. We demonstrate that selective knockdown of GJ gene Hve-inxl expression in single embryonic APs, by expressing a short-hairpin interfering RNA, leads to continued growth of the projections of the cell toward, into, and beyond adjacent ganglia. Moreover, the projections of the APs in adjacent ganglia also resume growth, mimicking their responses to cell deletion. Continued growth was also observed when two different INX1 mutant transgenes that abolish dye coupling between APs were expressed. These include a mutant transgene that effectively downregulates all GJ plaques that include the INX1 protein and a closed channel INX1 mutant that retains the adhesive cellular binding characteristic of INX1 GJs but not the open channel pore function. Our results add GJ intercellular communication to the list of molecular signaling mechanisms that can act as mediators of growth-inhibiting cell-cell interactions that define the topography of neuronal arbors.

\section{Introduction}

Interactions between neurons that define the extent of their arbors include reciprocal growth-inhibiting contacts between homologs leading to process retraction, a behavior termed homolog avoidance or neuronal tiling (Kramer and Kuwada, 1983; Kramer and Stent, 1985). This phenomenon has been described in a variety of animal systems, ranging from sensory neurons of the same modality in the body wall of the medicinal leech (Blackshaw et al., 1982; Kramer and Stent, 1985; Gan and Macagno, 1995) and Drosophila (Grueber et al., 2002) to cells in the different layers of the mammalian retina (Perry and Linden, 1982; Huckfeldt et al., 2009). This behavior, together with that of selfavoidance, or the repulsion between same-cell processes such as between the dendrites of a neuron, is believed to function to maximize the innervation of homologous neurons while maintaining non-overlapping coverage of a target area (Kramer and Stent, 1985; Wang and Macagno, 1998).

Mutant animals with defective neural tiling have been described in Drosophila, and this has led to the isolation of the cell

\footnotetext{
Received June 5, 2013; revised Sept. 9, 2013; accepted Sept. 13, 2013.

Author contributions: M.W.B. and E.R.M. designed research; M.W.B. and N.Y. performed research; M.W.B. and E.R.M. contributed unpublished reagents/analytic tools; M.W.B. and E.R.M. analyzed data; M.W.B. and E.R.M. wrote the paper.

This work was supported by National Science Foundation Grants DBI-0852081 and IBN-0446346 (E.R.M.). The authors declare no competing financial interests.

Correspondence should be addressed to Michael W. Baker or Eduardo R. Macagno, Section of Cell and Developmental Biology, University of California, San Diego, La Jolla, CA 92093. E-mail: mwbaker@ucsd.edu, emacagno@ucsd.edu.

N. Yazdani's present address: Boston University School of Medicine, 715 Albany Street, Boston, MA 02118.

DOI:10.1523/JNEUROSCI.2387-13.2013

Copyright $\odot 2013$ the authors $\quad 0270-6474 / 13 / 3316673-11 \$ 15.00 / 0$
}

surface Ig superfamily proteins DSCAM2 and TURTLE (Millard et al., 2007; Long et al., 2009), which together with the receptor protein tyrosine phosphatase LAR2 in the leech (Baker and Macagno, 2000; Baker et al., 2008), are known to be responsible for heteroneuronal repulsion. In addition, leech Lar2, along with DSCAM1 in the fly (Zipursky and Grueber, 2013) and protocadherin superfamily members in vertebrates (Lefebvre et al., 2012), appear to play critical roles in isoneuronal repulsion or self-avoidance.

Gap junction (GJ) proteins may provide another candidate signaling pathway for mediating interactions between branches of homologous neurons. In the developing leech CNS, the axonal projections of certain motor neurons, such as the AP neurons, display homolog avoidance behavior. Like most leech motor neurons, the adult APs extend projections out of the contralateral nerve roots to the body wall, where they branch extensively and are thought to modulate sensory neuron feedback (Gan and Macagno, 1995; Melinek and Muller, 1996). However, in the embryo APs also project axons anteriorly and posteriorly within the connective nerves (see Fig. $1 A-C$ ). When these projections meet the oppositely directed projections of their segmental homologs, they form GJs, stop growing and eventually retract completely (Gao and Macagno, 1987b; Wolszon et al., 1994b). Because ablation of an AP cell before this retraction occurs allows the projections of its homologs to resume their growth and take over the vacated territory of the killed cell (Gao and Macagno 1987a,b, 1988; Wolszon et al., 1994b), the possibility was raised that a GJ-based signaling mechanism might be responsible for cellular recognition between the AP axons and for causing the ensuing axonal retraction (Wolszon et al., 1995). 


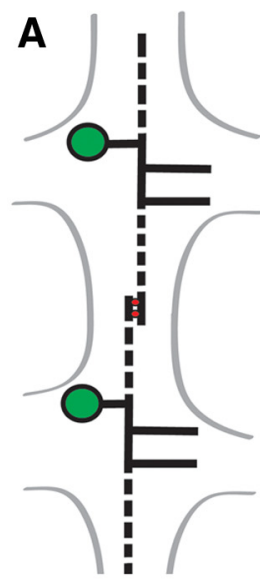

Embryonic

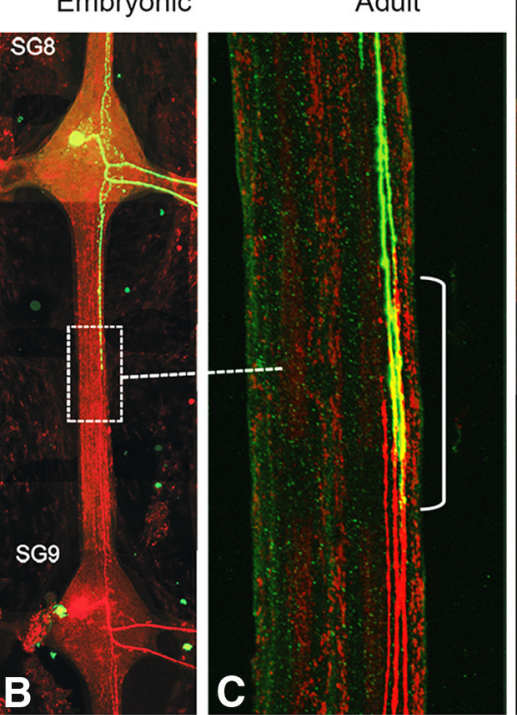

D

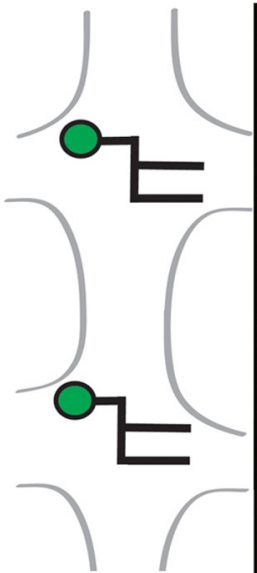

Adult
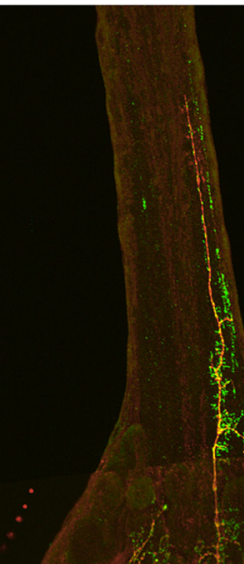

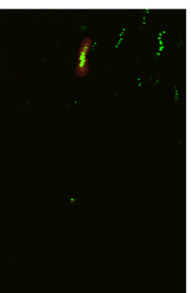

E
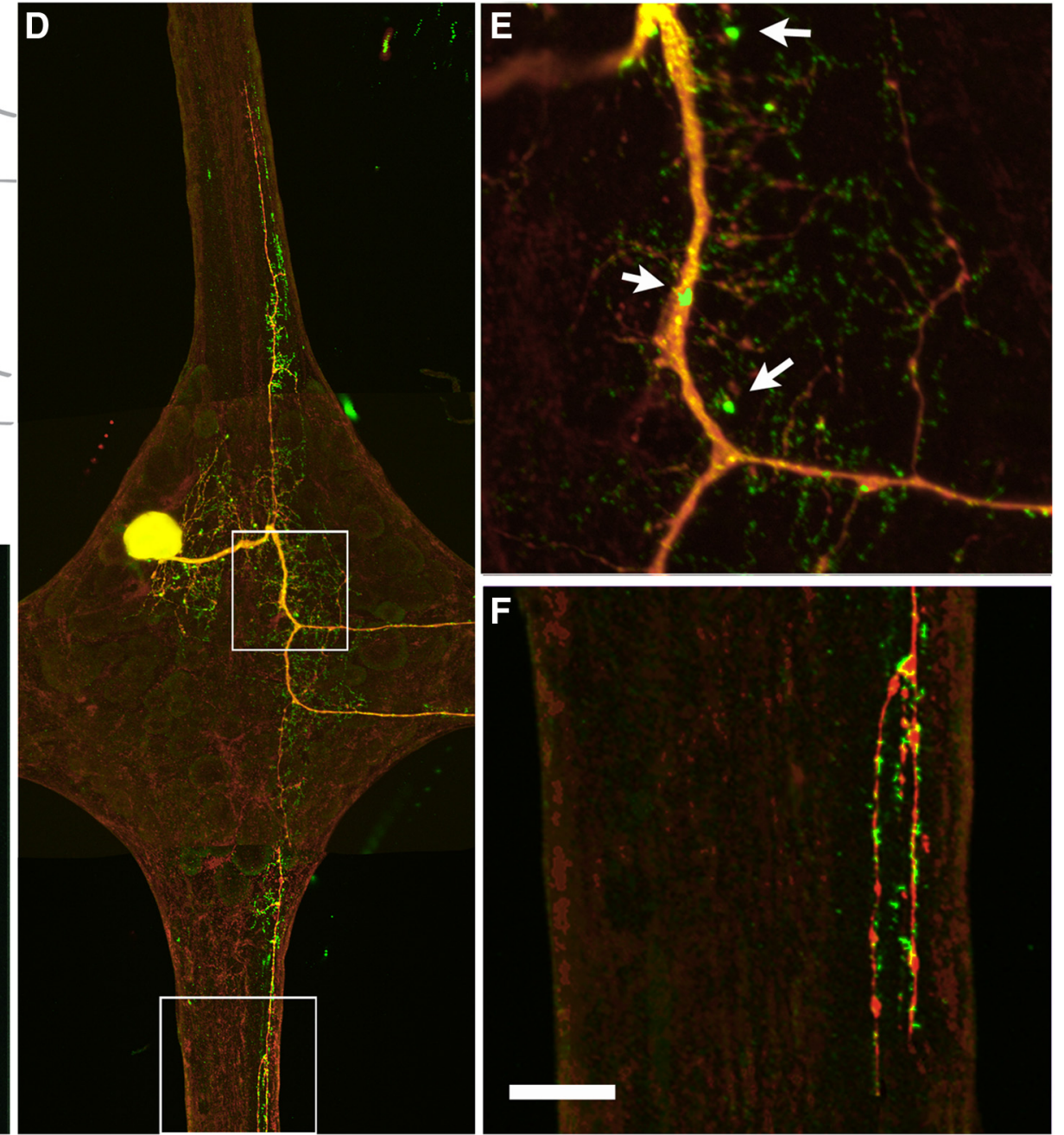

Figure 1. Morphology and distribution of INX1-EGFP in an AP neuron. A, Schematic representation of the embryonic and adult AP neurons in adjacent segmental ganglia. In the embryo, the AP neuron sends transient axons up and down the CNS connective (dashed lines) that, once contacting the axon from the adjacent segmental ganglion are retracted, yield the adult configuration. $\boldsymbol{B}$, Dye injections of Lucifer yellow and Neurobiotin/Alexa Fluor 568 Strepavidin staining of adjacent embryonic AP cells [segmental ganglia 8 (SG8) and 9 (SG9)] showing transient overlapping projections in the connective. $\boldsymbol{C}$, Enlargement of the boxed area shown in $\boldsymbol{B}$, indicating area of axon overlap (yellow). $\boldsymbol{D}$, INX1-EGFP transgene expression by a mid-embryonic AP neuron (day 17) at a time when the connective axon has begun to retract (red label from Neurobiotin dye fill). The transgene formed fluorescent puncta in the ganglionic neuropil and in the connective axon. $\boldsymbol{E}, \boldsymbol{F}$, Enlargements of the boxed areas in $\boldsymbol{D}$, showing clustered INX1-EGFP fluorescence. Scale bar, $30 \mu \mathrm{m}$.

Fifteen of the 21 innexin (Hve-inx) genes found in the genome of the medicinal leech, Hirudo verbana, are expressed in the CNS, of which the AP cells express high levels of Hve-inx1, 14 and 19, and lower but still significant levels of $H v e-i n x 4$ (Kandarian et al., 2012). Here we examine the effects of experimental perturbation of Hve-inx1 expression in the AP neuron to ask what role GJs might play in homolog avoidance.

\section{Materials and Methods}

Experimental animals. Hermaphroditic medicinal leech embryos were obtained from breeding colonies maintained at $22^{\circ} \mathrm{C}$ in our laboratory and that of Prof. William Kristan at the University of California, San Diego and staged according to established criteria (Fernández and Stent, 1982). At this temperature, day 0 (E0) is defined as the day of cocoon deposition and day 30 (E30) as the day of emergence of the juvenile animal from the cocoon. All expression and knockdown experiments were performed on embryos beginning at day 12-13.

Transgene construction and expression. Expression of wild-type INX1 and INX1-proline to leucine mutation (INX1-PL) was performed as described previously (Firme et al., 2012; Yazdani et al., 2013). Construction of an INX1 transgene with a leucine $\rightarrow$ tryptophan (INX1-LW) point mutation was accomplished using primers designed for site- directed mutagenesis of L (35) $\rightarrow \mathrm{W}$ for $\mathrm{Hve-inx1}$ using standard procedures (Sambrook et al., 1989). Cellular transformation was performed by direct intranuclear injection of neurons in the intact developing embryo (Baker and Macagno, 2006). Animals were allowed to develop for an additional 2-8 d before they were fixed, mounted in glycerol, and examined using a confocal microscope (Olympus FV1000). Neurobiotin injections were performed as described by Fan et al. (2005) and 5-HT injections as described by Wolszon et al. (1994b). Whole-mount indirect 5-HT immunofluorescence was performed using a goat anti-5-HT polyclonal antibody (diluted 1:200; ImmunoStar) and an Alexa Fluor 568 donkey anti-goat antibody diluted 1:500 (Invitrogen). In situ hybridization staining was performed as described by Nardelli-Haefliger and Shankland (1993). In situ hybridization staining intensities were measured using MetaMorph software by manually defining the boundary regions around the somas of individually stained neurons and determining the average gray level values above background.

RNAi of Hve-inx1 through intron-mediated short-hairpin micro-RNA expression. A short-hairpin RNA (shRNA) expression cassette was designed with a leech actin intron (HmAct1; GenBank accession number DQ333328, base pairs 1801-1956) inserted downstream of the ORF of EGFP (pEGFP-C3; Clontech) between the BglII and BamHI sites of the multiple cloning region. Using PCR mutagenesis, a stop codon was 

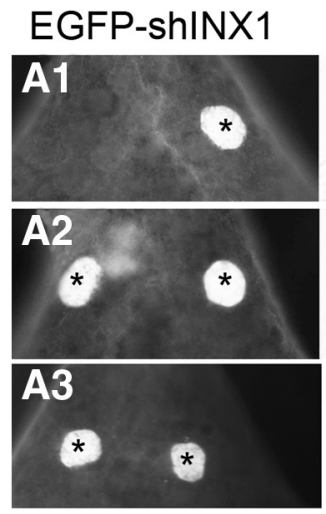

Hve-inx 1 ISH

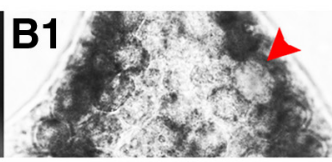

\section{B2}
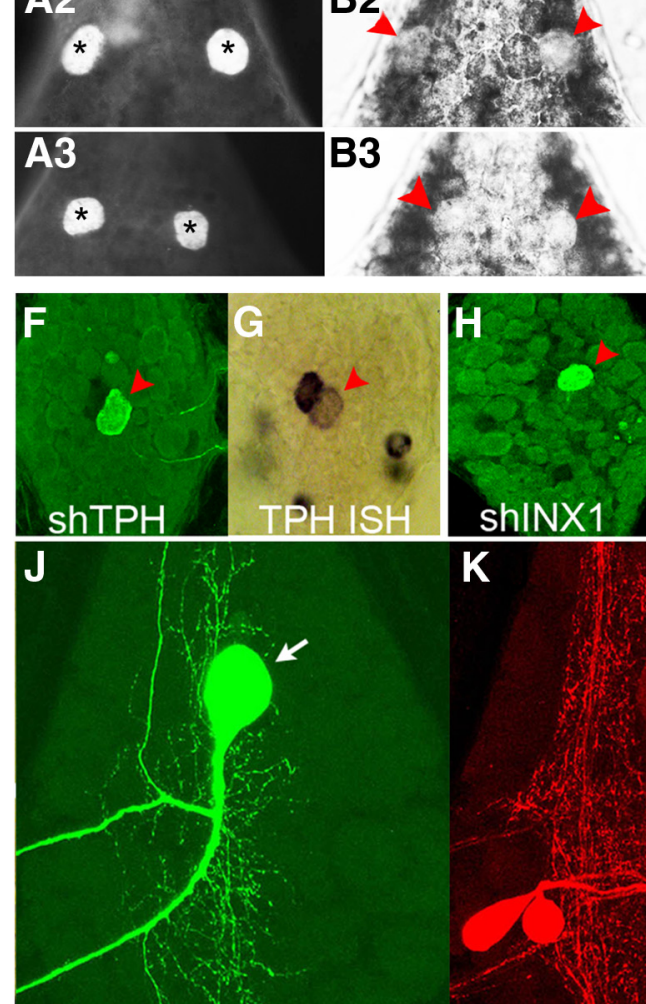

EGFP-shTPH

$\mathbf{K}$
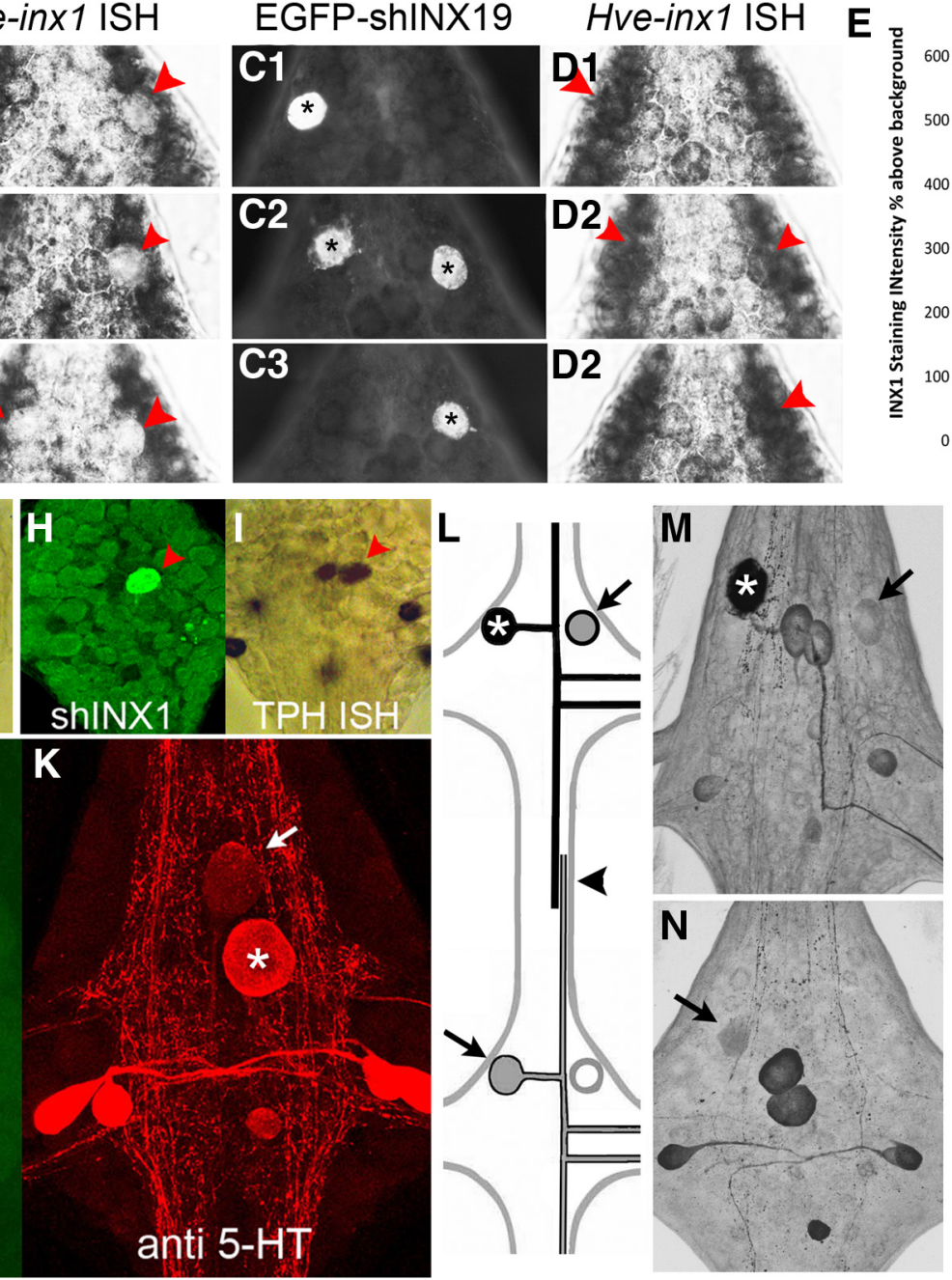

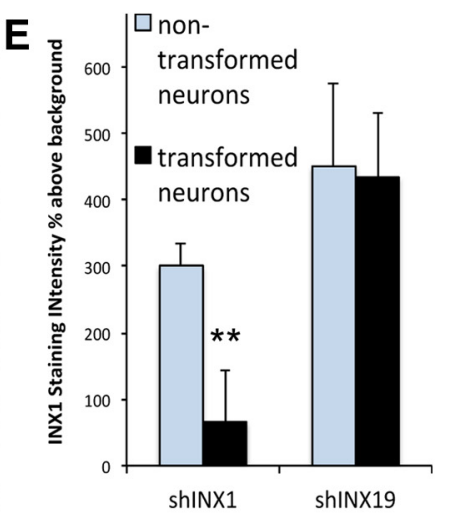

shINX1

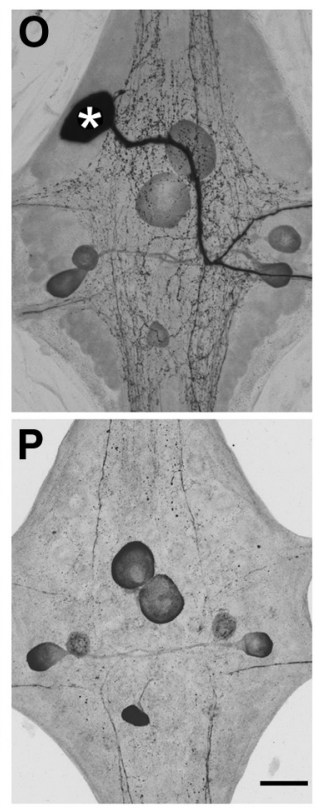

Figure 2. Expression of the intronic shINX1 plasmid selectively reduces Hve-inx $1 \mathrm{mRNA}$ levels and uncouples the AP neuron. $\boldsymbol{A}, \boldsymbol{B}, \mathrm{D}$ ouble labeling of embryonic $A \mathrm{P}$ neurons $48 \mathrm{~h}$ after expression of the EGFP-shINX1 reporter vector (A1-A3; asterisks indicate AP neurons) and in situ hybridization (ISH; $\boldsymbol{B} 1-\boldsymbol{B} 3$ ), revealing the loss of INX1 mRNA staining (red arrowheads). $\boldsymbol{C}, \boldsymbol{D}$, Control expression of an shRNA targeting INX19 (C1-C3; asterisks) fails to diminish INX1 mRNA labeling intensity (D1-D3; red arrowheads). $\boldsymbol{E}$, Quantification of INX1 mRNA staining intensity after shINX1 and INX19 expression. Values represent gray levels above background, corresponding to the location of the APs (transformed neurons; black bars) or nontransformed neurons adjacent to the APs (non-transformed neurons; gray bars). Data are $\pm S D\left({ }^{* *} p<0.01\right) . F-I$, The intronic shmiRNA system was specific to the targeted gene. Double labeling reveals that expressing a shmiRNA targeting tryptophan hydroxylase (TPH) in the serotonin (5-HT)-positive Rz neuron leads to a reduction in TPH mRNA labeling $(\boldsymbol{F}, \boldsymbol{G}$; red arrow) that was not observed when the Rz expressed the shmiRNA targeting INX1 (red arrowhead; $\boldsymbol{H}, \boldsymbol{I}$ ). $\boldsymbol{J}, \boldsymbol{K}$, Gene silencing of TPH leads to diminished 5-HT immunolabeling in the targeted cell. Reduced 5-HT immunolabeling is evident not just in the cell body of the Rz neuron ( $\boldsymbol{K}$; arrow compared with its segmental homolog; asterisk). $\boldsymbol{L}-\boldsymbol{P}$, Hve-inx1 gene silencing eliminates GJ tracer coupling by the AP neuron. $\boldsymbol{L}$, In mid-embryonic animals (E12-E15), during which time the axons of the APs are overlapping in the connective nerve (arrowhead in $\boldsymbol{L}$ ), tracer coupling between the AP cells can be reliably visualized by 5 -HT injection (asterisk) followed by 5 -HT immunoreactivity. Coupled AP neurons indicated by arrows. $\boldsymbol{M}, 5$-HT immunoreactivity $48 \mathrm{~h}$ after expression of a shINX19 transgene (asterisk). Note the presence of label in contralateral AP (arrow). N, 5-HT immunoreactivity in the adjacent posterior ganglion (SG9) to that shown in $\boldsymbol{M}$. Note the 5-HT AP labeling in the ipsilateral cell (arrow). $\mathbf{0}, \mathbf{P}, 5$ - $\mathrm{HT}$ immunoreactivity $48 \mathrm{~h}$ after expression of the shINX1 transgene (asterisk); no tracer coupling was seen in the contralateral AP neuron $(\boldsymbol{O})$ or in the ipsilateral AP cell of an adjacent ganglion $(\boldsymbol{P})$. Scale bars: $\boldsymbol{F}-\mathbf{I}, 75 \mu \mathrm{m}$; other panels, $45 \mu \mathrm{m}$.

placed $10 \mathrm{bp}$ in front of the intron, and the endonuclease restriction sites KpnI and PstI were inserted in the middle of the intron. Finally, the CMV promoter of pEGFP-C3 was excised between NdeI and AgeI and replaced by the proximal promoter region of HmActl (base pairs 1-1437). To target the Hve-inxl gene, a pair of complementary oligonucleotides were commercially synthesized that target the 21 bp sequence AAATCAGACAGCACTCTCGGA, which was reported previously to transiently silence Hve-inx1 (Todd et al., 2010). Each oligonucleotide included, respectively, a KpnI and PstI digested sequence at the $5^{\prime}$ and $3^{\prime}$ ends and a loop region [(CTTCCTGTCA); 5' - CAAATCAGACAGCACTCTCG GATCAAGAGTCCGAGAGTGCTGTCTGATTTCTGCA 3' and 5'-CA TGGTTTAGTCTGTCGTGAGAGCCTAGTTCTCAGGCTCTCACGAC AGACTAAAG (targeted complementary region underlined)]. Target sequences for gene silencing of leech tryptophan hydroxylase (TPH) and Hve-inx19 were selected using a Web-based program (www.idtdna.
com/Scitools/Applications/shRNA/). To target Hve-inx19, the 21 bp sequence CATCAAACTGCACCACGACTT was chosen, and to target leech TPH, the 21 bp target region GGTTTGGCCTATCGAGTCTTT was used. Complementary oligonucleotides were annealed together at a final concentration of $50 \mu \mathrm{M}$ each in an annealing buffer comprising 10 mm Tris-Cl, pH 8.0, 1 mм EDTA, pH 8.0, and $100 \mathrm{~mm} \mathrm{NaCl}$ and using a touchdown PCR program set for $30 \mathrm{~min}$ at $94^{\circ} \mathrm{C}$ and cooled by $1^{\circ} \mathrm{C}$ every 2 min down to $4^{\circ} \mathrm{C}$. Annealed oligonucleotides were kept on ice and diluted to $5 \mathrm{~nm}$ for ligation into KpnI and PstI digested A1-EGFP-intron vector.

Cell culture. S2 Drosophila cells were grown at $25^{\circ} \mathrm{C}$ in Schneider's Drosophila media (Invitrogen) with $10 \%$ heat-inactivated fetal bovine serum (catalog \#21720024; Invitrogen) containing 1\% penicillin-streptomycin solution (G6784; Sigma). Cells were seeded $1 \mathrm{~d}$ before transfection in six-well tissue culture plates (Greiner Bio-One). Calcium 
phosphate transfection was performed as described for the Drosophila Expression System (Invitrogen). The same Hve-inxl and Hveinx1-LW transgenes described above were used but with the leech actin promoter replaced with the Drosophila super core promoter 1 (Juven-Gershon et al., 2006).

The S2 cells were allowed to express for $48 \mathrm{~h}$ and were then subjected to cell aggregation assays by mixing equal volumes of cell suspensions in polystyrene $35 \mathrm{~mm}$ dishes and agitating them using a rotary shaker at $100 \mathrm{rpm}$ for $20 \mathrm{~min}$. The cellular aggregates were then counted without mounting using a Nikon Eclipse E600 microscope equipped with a $20 \times 1$ $0.50 \mathrm{~W}$ numerical aperture Plan Apo differential interference contrast water-immersion objective and a Cooke Sensicam QE CCD camera. For quantification, the number of cells in aggregates, the number of aggregates per field, and the number of single cells per field were counted in a minimum of five different fields. Clusters of more than five cells were considered an aggregate. Experiments were performed in triplicate.

Statistical analyses. We used Fisher's exact test to analyze AP sprouting. In all cases, a twotailed $p$ value was obtained using StatPlus. Measurements for the $\mathrm{S} 2$ cell aggregation assay are given in mean $\pm \mathrm{SE}$. Statistical significances for multiple grouped data were determined by two-way ANOVA in Excel, followed by the paired Student's $t$ tests to look for similarities and differences between groups.

\section{Results}

INX1 is present in GJs located at the site of $\mathrm{AP}-\mathrm{AP}$ interactions in the

\section{connective nerves}

Previously we demonstrated that the pan-neuronal leech innexin Hve-inx1 plays a necessary role in the formation of GJs between most central neurons, as demonstrated by the abolishment of dye coupling after neuronal expression of a dominant-negative mutant of this protein (Yazdani et al., 2013). Accordingly, we selected Hve-inx1 for our studies of GJs and AP homolog avoidance. Because GJ proteins can be heterogeneously distributed within the arbor of a leech neuron (Yazdani et al., 2013), we first checked that INX1 is indeed present at the location in the connective nerves in which AP homologs are known to form GJs (Wolszon et al., 1994b). Because INX1 is expressed by most if not all central leech neurons, we chose to visualize GJ plaques containing INX1 by expressing an INX1 transgene with a $\mathrm{COOH}-$ terminal EGFP tag in single AP neurons (Fig. $1 D-F$ ). Previous studies have shown that such INX transgenes faithfully reproduced the punctate pattern observed when staining the ganglion with an INX antibody, except that there was additional diffuse fluorescence in the cell body, which was attributed to higher expression levels of the transgene (Firme et al., 2012; Yazdani et al., 2013). Critically, these studies also demonstrated that the INX transgenes were capable of forming functional GJs indicating that at least some of the fluorescent puncta represented GJ plaques. The INX1 transgene in the AP neuron also produced a diffuse fluorescence throughout the arbor of the cell but with large punctate fluorescence along and near the primary processes of the cell and smaller puncta in many of the finer processes (Fig. 1E). In addition, a strong fluorescence was seen in the connective axons
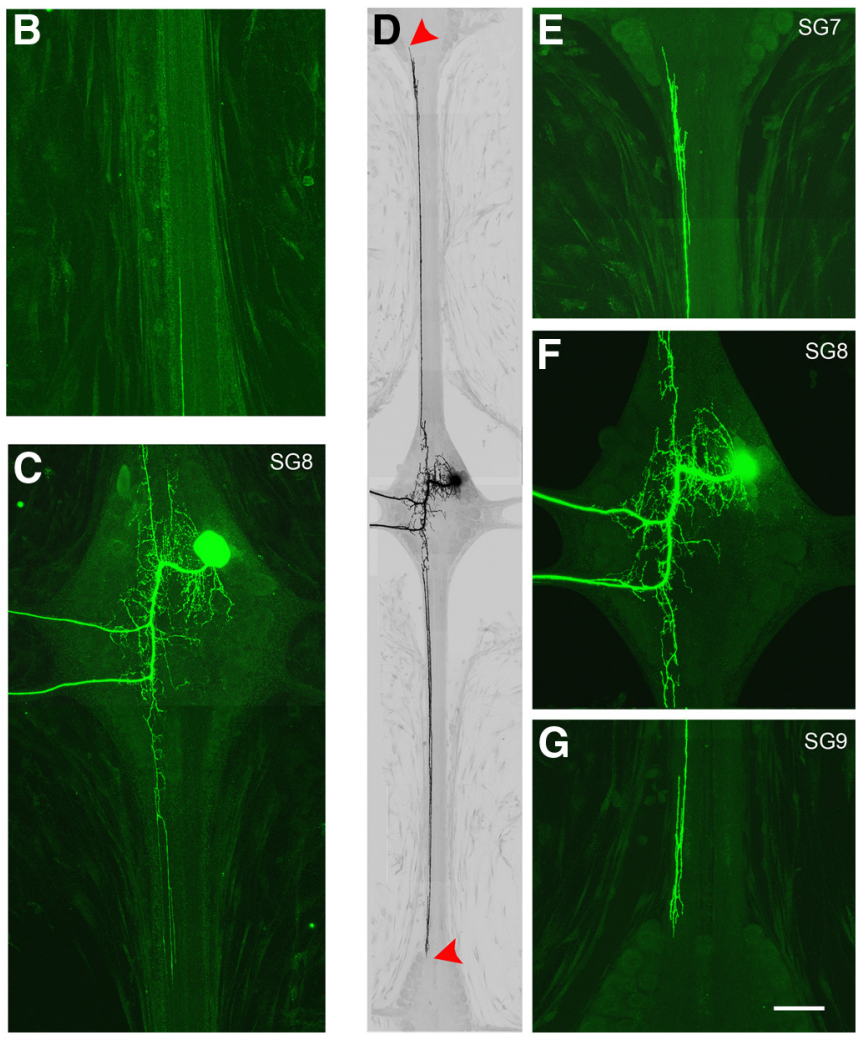

\section{.}

Figure 3. The AP neuron continues to extend its interganglionic axons after INX1 knockdown. $\boldsymbol{A}$, Composite image of an AP cell posterior ganglia (red arrowheads). $\boldsymbol{E}-\boldsymbol{G}$, Higher-magnification views of the cell in $\boldsymbol{D}$, showing a more complex leading tip, with numerous filopodia $(\boldsymbol{E}, \boldsymbol{G})$. Scale bar: $\boldsymbol{A}, \boldsymbol{D}, 120 \mu \mathrm{m}$; other panels, $60 \mu \mathrm{m}$.

of the neuron (Fig. $1 F$ ). Because the AP cell shown in Figure $1 D-F$ was of an age when axon retraction in the connective would be expected to have already commenced, it is likely that the larger clusters correspond to the accumulation of fluorescent INX1 in internal recycling bodies, such as endosomes. Finally, expressing the INX1 transgene did not appear to affect normal AP axon homolog avoidance, because older preparations were observed with complete connective axon collapse after expressing the transgene (data not shown).

In summary, these observations of INX1 GJ protein localization in the AP connective axons in which they interact with homologs complement past physiological tracer-passage and EM reconstruction studies, showing the presence of this GJ protein in the connective axon.

\section{Evaluation of efficacy and specificity of intronic short-hairpin micro-RNA transgenes}

RNAi in the leech has been performed successfully at the singlecell level through the direct injection of dsRNAs into the cytoplasm of identified cells and neurons (Baker and Macagno, 2000; Samuels et al., 2010; Todd et al., 2010). However, concern regarding the long-term effectiveness of knockdown led us to adopt a plasmid-based shRNA expression system (Fig. 2) that takes advantage of the fact that some short-hairpin micro-RNAs (shmiRNAs) are found within the introns of transcripts (Stegmeier et al., 2005; Qiu et al., 2008). In such a manner, a single pre-mRNA transcript can allow for the production of a reporter transcript 


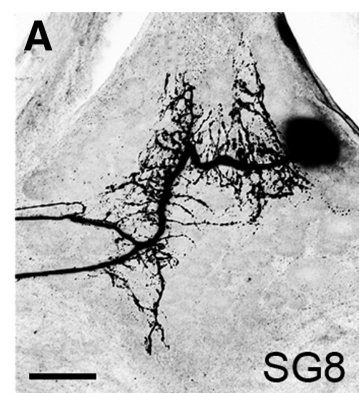

Axon restricted to local segmental ganglion

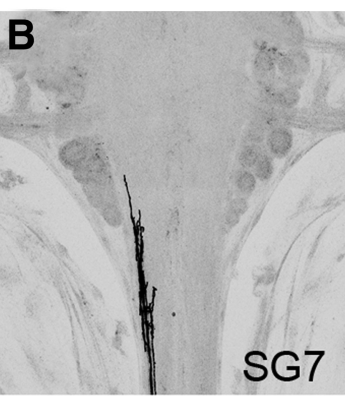

Axon entering adjacent segmental ganglion

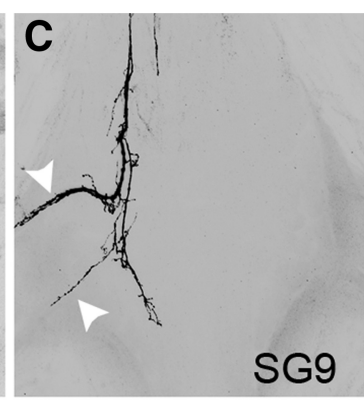

Projections exiting Processes beyond adjacent adjacent roots of ganglion

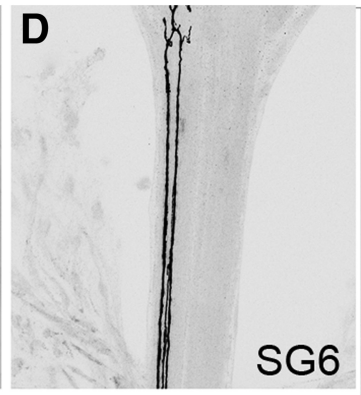

segmental ganglion

\begin{tabular}{|c|c|c|c|c|c|}
\hline & $\begin{array}{l}\text { Axon in } \\
\text { segmental } \\
\text { ganglion }\end{array}$ & $\begin{array}{l}\text { Axon adjacent } \\
\text { to } \\
\text { extrasegmenta } \\
\text { I ganglion }\end{array}$ & $\begin{array}{l}\text { Projections in } \\
\text { extra- } \\
\text { segmental } \\
\text { roots }\end{array}$ & $\begin{array}{l}\text { Axons beyond } \\
\text { extra- } \\
\text { segmental } \\
\text { ganglion }\end{array}$ & $\begin{array}{l}\text { Two-tailed p-value } \\
\text { (Fisher's exact test) }\end{array}$ \\
\hline $\begin{array}{l}\text { control dye } \\
\text { injection + } \\
\text { EGFP }\end{array}$ & $13(92.9 \%)$ & $1(7 \%)$ & 0 & 0 & \\
\hline shINX19 & $13(86.7 \%)$ & $3(20 \%)$ & 0 & 0 & vs. control $p=0.6$ \\
\hline shINX1 & $2(14.3 \%)$ & $12(85.6 \%)$ & $4(28.6 \%)$ & $3(21.3 \%)$ & $\begin{array}{l}\text { vs. control } p<0.0001 \\
\text { vs. INX1P149L } p=0.84 \\
\text { vs. INX1L35W } p=0.99\end{array}$ \\
\hline INX1P149L & $1(12.5 \%)$ & $7(87.5 \%)$ & $3(37.5 \%)$ & 0 & $\begin{array}{l}\text { vs. control } p<0.0001 \\
\text { vs. INX1L35W } p=0.87\end{array}$ \\
\hline INX1L35W & 0 & $7(100 \%)$ & $2(25 \%)$ & $1(12.5 \%)$ & vs. control $p<0.0001$ \\
\hline
\end{tabular}

Figure 4. Quantification of AP growth after INX1 perturbation. $A-D, A P$ neuron morphology was classified into one of the following. $A$, AP with no axons in the anterior or posterior connective (example shown after shINX19). $\boldsymbol{B}$, AP (in SG8) axon entering the adjacent anterior segmental ganglion (SG7) (after shINX1). $\boldsymbol{C}$, AP (in SG8) axon branching in the posterior adjacent segmental ganglion (SG9) with projections extending out the nerve roots (white arrowheads; after INX1PL expression). D, AP (SG8) axon entering ganglion two segments anterior (SG6) (after shINX1). Scale bar, $50 \mu \mathrm{m}$. Most preparations receiving control dye fills or shlnx19 expression (targeting a different innexin gene expressed by the AP neuron) had axons restricted to the local segmental ganglion (black and dark bars; $n=15$ of 17), those expressing the shINX1 (diagonal bars; $n=12$ of 14), or INX1-PL dominant-negative transgene (light gray bars; $n=5$ of 6 ) or the INX1-LW channel-null mutant (horizontal bars; $n=7$ of 7 ) had axons extending into the adjacent ganglion and in some instances out of the contralateral roots or beyond the next segmental ganglion.

such as EGFP along with the intronic shRNA, thereby greatly facilitating the tracking of shRNA production in individual cells and the screening of knockdown effectiveness, particularly within tissues in vivo (Haley et al., 2008).

The effectiveness of the shmiRNA vector in knocking down Hveinx1 mRNA was tested using whole-mount in situ hybridization of the embryo after single AP cell expression of the hairpin. Hve-inx1 mRNA labeling was found to be significantly reduced in neurons expressing the plasmid (Fig. 2A1-A3,B1-B3,E). In contrast, expressing a different shmiRNA targeting $H v e-i n \times 19$ (Fig. 2C1-C3,D1$D 3, E)$, which is also expressed by the AP neuron, did not significantly alter Hve-inx1 mRNA labeling compared with nontransformed neighboring neurons (Fig. $2 E$ ). The specificity of the intronic shmiRNA system for gene silencing was further tested by a series of experiments targeting a different mRNA: tryptophan hydroxylase (TPH). TPH mRNA labeling in Retzius (Rz) neurons expressing the shmiRNA transgene targeting TPH was visibly reduced after 3-4 d (Fig. $2 F, G$ ). Furthermore, TPH mRNA staining was not noticeably affected when the same $\mathrm{Rz}$ cells expressed the shmiRNA targeting INX1 (Fig. $2 H, I$ ), indicating that the shINX1 sequence does not shut down all DNA transcription. Finally, an obvious reduction in serotonin (5-HT) immunoreactivity in the soma of the Rz neuron and major processes was observed after knockdown of TPH (Fig. $2 J, K)$.

Previous studies from our laboratory have shown persistent tracer coupling between the bilateral APs in the same ganglion from E12 onward through intracellular injections of 5-HT [molecular weight (MW) 212], which is then detected in the soma of the coupled cell by 5-HT immunoreactivity (Wolszon et al., 1994b). Furthermore, in embryos from E13 to E15, when the axons of the APs overlap in the connective nerve, 5-HT injections also reliably label the ipsilateral APs in adjacent anterior and posterior ganglia (Fig. $2 L-N$ ). In contrast, Neurobiotin (MW 322), 5,6-carboxyfluorescein (MW 376), or Lucifer yellow (MW 459) all fail to behave as GJ tracers when injected into the AP cell, regardless of developmental age (Wolszon et al., 1994b; our unpublished results). Therefore, we used 5-HT injections into the AP cell to test for GJ coupling after expressing the intronic shmiRNA targeting INX1. In five of six cases when the EGFP shINX1 reporter construct was strongly expressed, 5-HT coupling to the contralateral AP neuron was abolished (Fig. 2O), and in all six cases coupling to the adjacent ganglia AP cells was eliminated (Fig. 1P). This effect also appeared to be persistent, because it was observed in animals up to $25 \mathrm{~d}$ of development 
$(n=3)$. In contrast, expression of the shmiRNA without a hairpin insert or with the shINX19 sequence resulted in the 5-HT coupling being maintained with the contralateral AP in all ages tested (Fig. $2 M ; n=9$ ) and with the ipsilateral APs in adjacent ganglia in preparations younger than E15 (Fig. $2 N ; n=8$ ). Therefore, we conclude that the shINX1 intronic transgene provides effective, long-lasting gene silencing of Hve-inxl and that it effectively abolishes GJ tracer coupling between the AP neurons.

\section{Hve-inx1 gene silencing in AP neurons leads to the continued growth of their connective nerve projections in the presence of those of their homologs}

To assay for possible effects of Hve-inxl knockdown on the projections of the AP neuron, we examined their branches in the interganglionic nerves beginning at E20, 5-8 d after AP-AP interaction is taking place and at a developmental stage when the axons of the AP in the connective have either fully, or at least partially, retracted (Gao and Macagno, 1987b; Wolszon et al., 1994b; Gan and Macagno, 1997). Figure 3A-C shows a composite image of an AP neuron in the CNS at E20, $7 \mathrm{~d}$ after expression of the empty shmiRNA expression vector. The tips of the connective axons are demarcated by the red arrowheads, which reveal that the anteriorly and posteriorly directed projections extend only into the beginning of the central connective and no farther. In contrast, $7 \mathrm{~d}$ after expressing the shINX1 transgene, EGFP labeling in a representative AP cell reveals that the central projections have continued to extend and have begun to enter the ganglia of the anterior and posterior neighboring segments (Fig. 3D-G). The morphology of their growing tips closely resembles those seen earlier in development. Because these projections are still actively extending in the connective, their features include flattened regions (lamellipodia) and numerous branches and filopodia (Wolszon et al., 1994b; Fig. 3 E, G), in strong contrast to the controls, which display thin, single tips devoid of filopodia (Fig. $3 B)$. However, no differences were observed in the neuropil arbors between experimental animals and controls. In both cases, the AP neurons maintained their strict contralateral projections, and no instances of neurites in the ipsilateral nerve roots were observed.

The extent of sprouting by an AP after INX1 knockdown varied considerably among experiments (Fig. 4). Although most preparations showed sprouting and growth by the axon in the adjacent connectives ( $85 \% ; n=12$ of 14 ), close to $25 \%$ also displayed longer processes entering the adjacent segmental ganglia and extending out to the periphery within their nerve roots, and $12 \%$ of the AP cells had projections extending beyond the adjacent ganglia toward the next ganglionic segment (Fig. 4D). This can be contrasted with only $19 \%$ ( $n=3$ of 16 ) of AP cells after shmiRNA INX19 expression, which displayed projections close to a neighboring ganglion but none that had grown farther.

It is worth considering that, although the extraganglionic AP axons are known to form overlapping projections in the CNS connective between the ages of E12 and E15, we were only able to begin gene silencing after E12. The fragility of the embryo and neurons at earlier stages makes transgene expression by direct nucleus injection impractical before this time. Thus, the variable phenotypes we report here are likely to be the result of only a partial knockdown of Hve-inxl at the beginning of AP-AP contact and interaction.

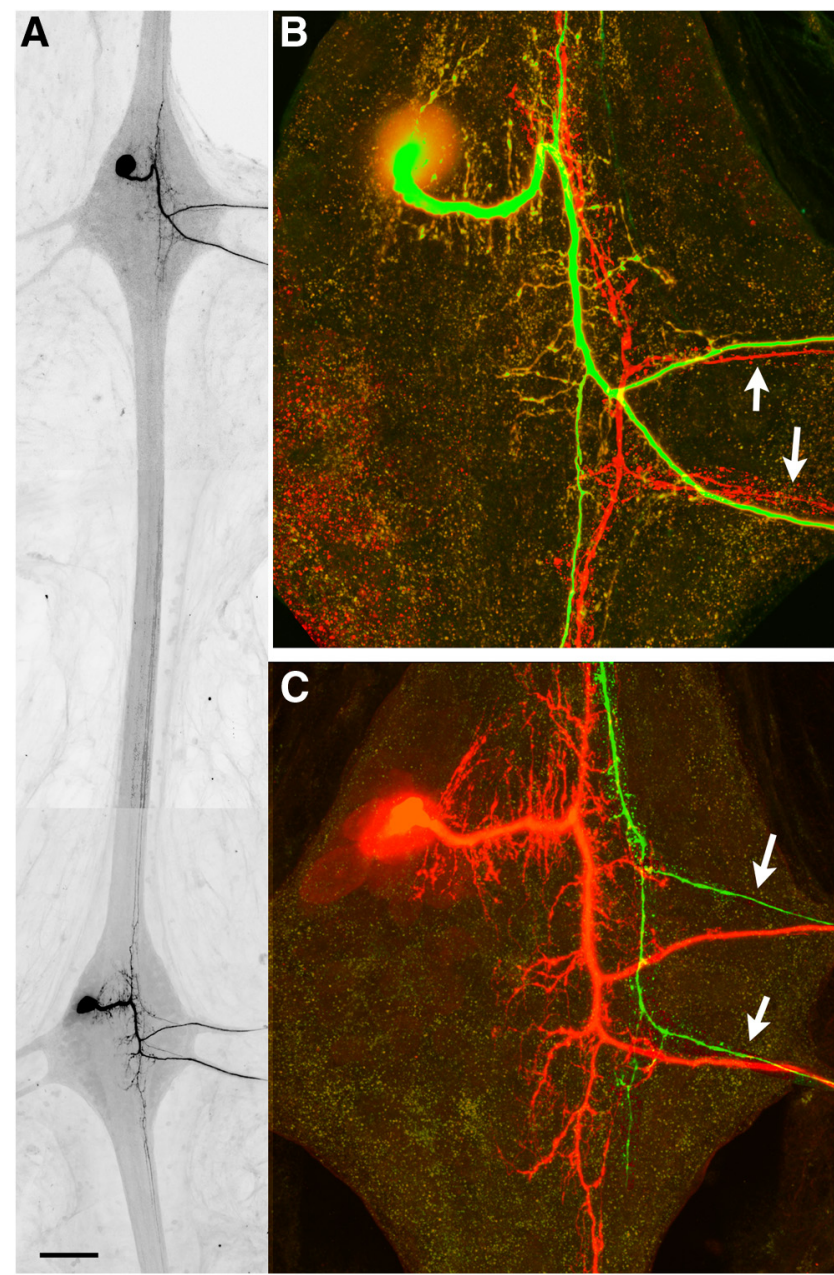

Figure 5. Loss of INX1 GJ signaling in the AP neuron leads to sprouting by the extrasegmental untreated AP homolog. $A$, Composite image of two adjacent ganglia. The shINX1 transgene was expressed in the AP cell of the top ganglion for $7 d$, after which time the ipsilateral AP neuron of the extrasegmental ganglion (bottom ganglion) was injected with Neurobiotindextran. $\boldsymbol{B}, \boldsymbol{C}$, Higher-magnification view of the shINX1-expressing AP neuron (EGFP; $\boldsymbol{B}$ ) and the extrasegmental AP neuron (red label; $\boldsymbol{C}$ ). In this example, both the shINX1-expressing AP and the extrasegmental AP have continued to extend their connective axons into the adjacent ganglion and extend projections out the contralateral nerve roots (arrows). Scale bar: $\boldsymbol{A}, 200$ $\mu \mathrm{m} ; \boldsymbol{B}, \boldsymbol{C}, 30 \mu \mathrm{m}$.

\section{Hve-inx1 gene silencing in an AP results in maintained growth by the connective nerve projections of its homologs in neighboring segments}

Next we also sought to assay the morphology of the homologs in adjacent ganglia after INX1 knockdown in an AP neuron. The homologs, while receiving no direct experimental perturbation, might be expected to also be relieved of any inhibitory signal mediated through the AP-AP GJ and to phenocopy the growth seen after AP deletion (Gao and Macagno, 1987b). Accordingly, we dye filled the ipsilateral extrasegmental AP neurons in the adjacent anterior and posterior ganglia after INX1 knockdown. Significant maintained growth was observed in five of eight successful preparations, with projections close to or beyond the neighboring segmental ganglion; three of these had processes extending out of the contralateral nerve roots of the neighboring ganglion (Fig. 5, arrows).

Together, these data confirm that GJ signaling is responsible for AP-AP neuron homolog avoidance. Knocking down Hve-inx1 levels leads to continued growth by the connective axons of the AP 

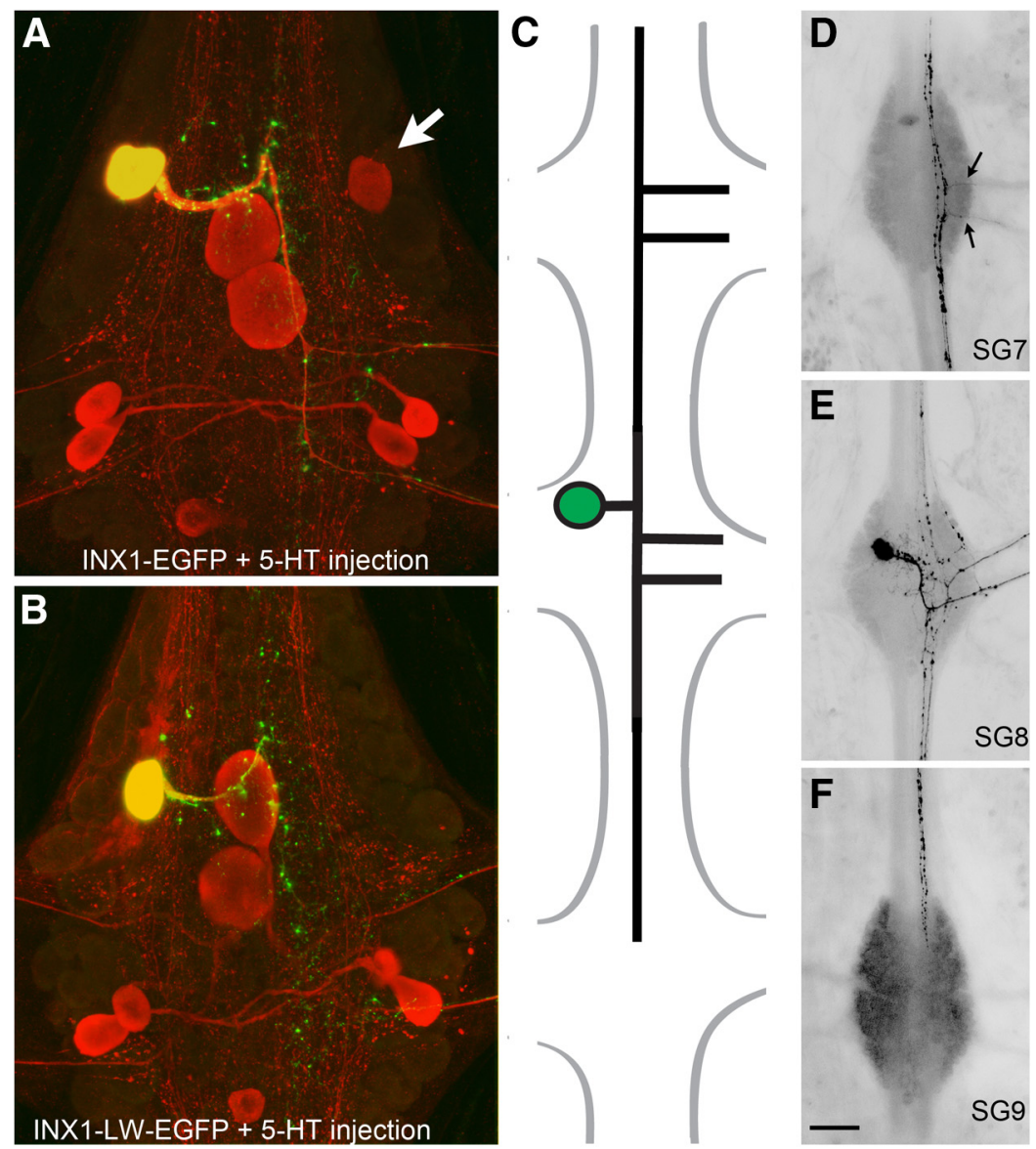

Figure 6. Sprouting by the AP neuron connective axon after expressing a channel-null INX1 transgene (INX1-LW). $A$, Serotonin tracer coupling with the contralateral AP neuron (arrow) after expressing wild-type INX1. Note the 5-HT coupling to the contralateral AP neuron (arrow). B, Loss of 5-HT coupling after expressing the channel-null mutant. Note that, despite the loss of coupling, the mutant transgene punctal distribution closely resembles that of the wild type, suggesting that normal GJ formation is not affected. $\boldsymbol{C}$, Representation of AP sprouting $5 \mathrm{~d}$ after INX1-LW expression. The AP neuron ( $\boldsymbol{E}$ ) has extended its connective axon into the anterior segmental ganglion $(\boldsymbol{D})$ and out of the contralateral roots (arrows) and into the posterior segmental ganglion $(\boldsymbol{F})$. Scale bar: $\boldsymbol{A}, \boldsymbol{B}, 30 \mu \mathrm{m} ; \boldsymbol{D}-\boldsymbol{F}, 100 \mu \mathrm{m}$.

neurons. Moreover, this GJ-dependent inhibition of growth is symmetrical, affecting not just the experimental AP neuron but also its unperturbed extrasegmental homologs.

\section{Maintained AP axon growth is phenocopied by expressing a dominant-negative INX1 transgene}

A highly conserved (or convergent) proline residue (amino acid 120 in INX1) is found in the second transmembrane domain of all innexins and pannexins and many connexins (Phelan, 2005). Studies with connexins describe this proline as introducing a kink into the three-dimensional structure of the protein, and mutation of the proline to leucine in Cx26 has been shown to impart a dominant-negative effect on all connexons composed of the mutated GJ protein subunit (Suchyna et al., 1993; Ri et al., 1999; Ambrosi et al., 2010). Likewise, leech INX1-PL leads to a loss of transgene puncta when it is expressed in neurons and the uncoupling of INX1 gap junctional communication (Yazdani et al., 2013). Therefore, we examined the effects on growth of the connective axons when the AP neuron expressed the INX1-PL transgene. Because the INX1-PL transgene typically did not produce strong fluorescent labeling in the processes of neurons, we used Lucifer yellow or Neurobiotin dye injections to label the arbor of the cell. The INX1-PL transgene was expressed in eight AP cells, seven of which displayed maintained growth reaching to the neighboring ganglia or beyond, with three of them growing out of the neighbor's roots (Fig. 4C). One of the eight resembled the control shINX19 APs or control dye fills and had no sprouted axons.

Thus, expressing the INX1-PL transgene mimics the effects of INX1 RNAi, leading the connective axons to sprout and grow past their extrasegmental homologs.

\section{INX1-mediated AP homolog avoidance requires a functional $\mathrm{GJ}$ pore}

In addition to coupling cells electrically, GJs allow for the direct intercytoplasmic exchange of small molecules. Moreover, innexons and pannexons have been shown to mediate the extracellular release of signaling molecules, such as ATP (Bao et al., 2004; Samuels et al., 2010). Interestingly, in their roles in cortical neuronal migration, connexins have been shown to have a purely adhesive role, providing dynamic adhesive contacts with radial glial cells in the absence of intercytoplasmic molecular signaling (Elias et al., 2007). To test whether this might also be the case for the role of INX1 in AP-AP avoidance, we examined the effects of expressing a mutant INX1 transgene that formed a nonfunctional (closed) channel but was still capable of docking with an apposed innexon and presumably mediating an adhesive interaction. Critical protein residues within the transmembrane regions of GJ proteins help control the permeation and gating of the channel, and several connexin point mutations within the transmembrane regions have been isolated and shown to allow for the formation of closed-channel GJs that retains their adhesive function (Beahm et al., 2006; Elias et al., 2007). We sought to obtain an equivalent INX1 mutant by mutating a highly conserved/convergent leucine found in the first transmembrane domain of most innexins, pannexins, and connexins (Phelan 2005) and which when switched to tryptophan in the Drosophila Shak(B) innexin has been shown to reduce GJ coupling by $>30$-fold when expressed in Xenopus oocytes and paired with the wild-type Shak(B) innexon (Depriest et al., 2011).

When this mutant INX1 (INX1-LW; L35 $\rightarrow$ W) was expressed in the embryo, it led to the formation of normal looking puncta within the arbors of central neurons (Fig. 6A,B), but when INX1-LW was expressed in one of the AP neurons and $3 \mathrm{~d}$ later it was injected with 5-HT, no 5-HT immunoreactivity was detected in the contralateral APs $(n=4$; Fig. $6 A, B)$, indicating that normal AP-AP tracer coupling was abolished.

Although the presence of fluorescent puncta in these neurons indicated that GJ plaques were still being made in the absence of tracer exchange, we sought to directly test the adhesive properties of INX1-LW by expressing the mutant innexin in cultured cells and performing cellular aggregation assays. Drosophila S2 cells transiently transfected with wild-type leech innexins reliably aggregate into innexin-specific cellular clusters (Fig. 7). For INX1, this aggregation was selective for INX1-expressing cells. When 

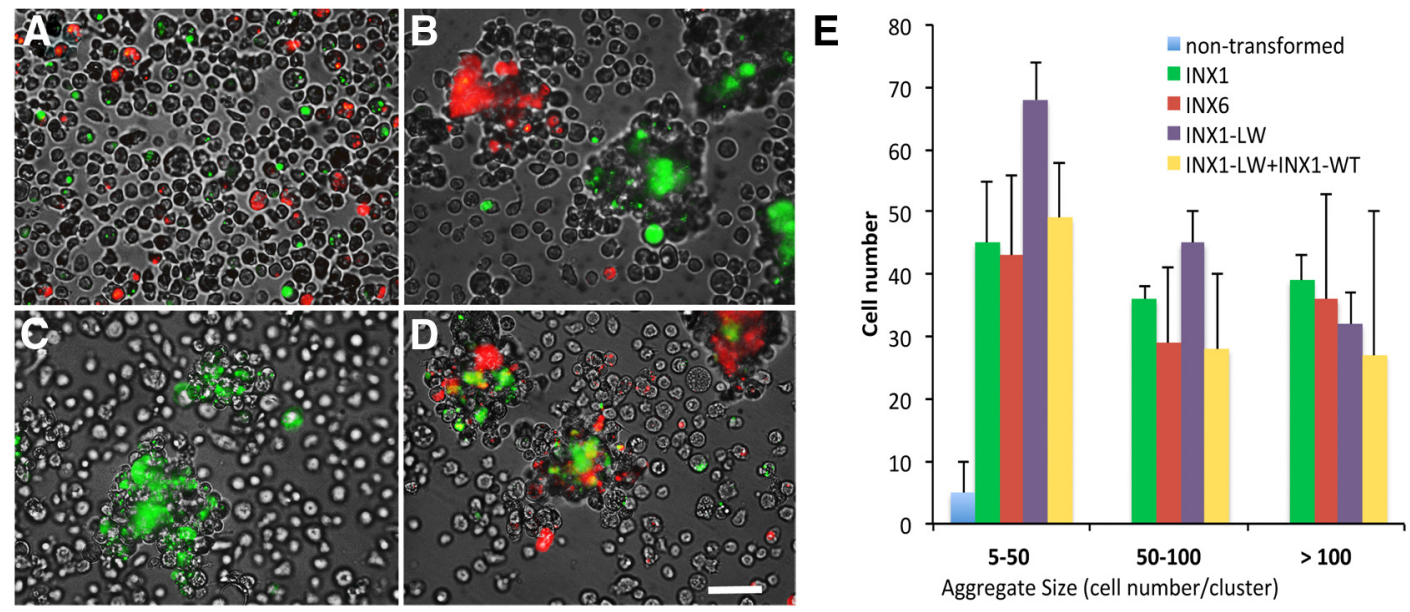

Figure 7. Aggregation of $S 2$ cells expressing leech innexins. $\boldsymbol{A}$, Representative image of a mixture of INX1-EGFP, INX6-mCherry, and non-expressing cells immediately after suspension in the media. $\boldsymbol{B}$, Formation of INX1-EGFP and INX6 - mCherry aggregates after mixing on an orbital shaker for 20 min. $\boldsymbol{C}$, Formation of INX1-LW aggregates indicating that the mutation does not disrupt INX1-dependent adhesion. $\boldsymbol{D}$, Cellular adhesion between INX1-LW-EGFP-expressing and wild-type INX1-mCherry-expressing cells indicating that INX1-LW maintains the ability to selectively bind to wild-type INX1. Scale bar, $30 \mu \mathrm{m}$. $E$, The number of cells in each aggregate according to type of expression. The $x$-axis represents cell aggregate sizes of 5-50,50-100, and $>100$ cells per aggregate. The $y$-axis represents the number of each case. The bars indicate the means of five samples from three independent results. Error bars indicate the SE. Two-way ANOVA showed a significant effect between nontransformed and innexin transformed cells $\left(F_{(4,43)}=9.06, p=0.004\right)$ but no significant differences in aggregate sizes $\left(F_{(2,43)}=1.86, p=0.21\right)$.

cultures of INX1-EGFP- and INX6-mCherry-expressing cells, a leech neuronal innexin that is selectively expressed by only three neurons in each ganglion (Dykes and Macagno, 2006), were mixed together, INX1 aggregates and INX6 aggregates were separately formed with very little mixing (Fig. $7 B$ ), suggesting that at least for monomeric INX1 and INX6 hexamers, heterotypic GJs do not form. Importantly, S2 cells expressing the INX1-LW mutant showed a similar tendency to aggregate as the wild-type INX1 (Fig. 7C). Finally, these aggregates were observed to form not only with other INX1-LW-expressing cells but also wild-type INX1 cells (Fig. 7D), suggesting that the $\mathrm{L} \rightarrow \mathrm{W}$ mutation does not prevent the ability of the monomeric INX1-LW innexon from docking with other wild-type INX1 innexons. Thus, although we cannot rule out other subtle changes produced by INX1-LW, expressing the mutant transgene blocks normal AP-AP GJ tracer passage while still allowing the formation of characteristic GJ puncta in the AP neuronal arbor. Furthermore, the INX1-LW protein retains similar adhesive characteristics as the wild-type INX1, suggesting that only the GJ pore is significantly perturbed.

When the INX1-LW mutant was expressed in E12 AP neurons, the connective axons were observed to continue to extend, mimicking the effects of INX1 knockdown and the INX1-PL mutant (Figs. 4, 6C-F). The INX1-LW transgene was expressed in seven AP cells, and all had axons in or near the anterior and posterior neighboring ganglia, with three of the cells extending their processes out of at least one of the adjacent roots of the ganglion (Figs. 4, 6D, arrows).

These findings provide support for the view that AP intercellular GJ communication is a necessary requirement for AP homolog avoidance.

\section{Discussion}

A common feature of early nervous system development is the widespread coupling of cells through GJs, many of which become downregulated as the nervous system matures. Uncoupling has been seen at the time of axon outgrowth (Goodman and Spitzer, 1979; Kramer and Kuwada, 1983), as well as dur- ing axonal pathfinding at decision points, such as while interacting with guidepost cells (Taghert et al., 1982). GJ-coupled cellular networks also appear to define functional domains within the developing nervous system in which they have been speculated to help regulate everything from synapse and circuit formation to cellular proliferation, migration, and death (Lopresti et al., 1974; Cusato et al., 2003; Cheng et al., 2004; Elias et al., 2007; Firme et al., 2012). We can now add neuronal homolog avoidance to the list of cellular developmental phenomena mediated by GJs.

\section{AP-AP GJ signaling}

We have shown that the knockdown in a single AP neuron of the expression of Hve-inxl, a necessary component of AP GJs, uncouples this neuron from its normal network and renders it unresponsive to its homologs, allowing it to grow into territory from where it is normally excluded and, reciprocally, permitting its homologs to innervate its territory in its presence.

A number of critical questions are raised by these results. For example, how does the AP-AP GJ-mediated interaction lead to process retraction but interactions between projections of other homologous neurons that also involve GJ coupling result in stabilization of the coupled projections? A good example of this behavior is the $S$ interneurons. Each segmental ganglion in the leech CNS contains a single S cell, whose large axons form stable electrical synapses in the middle of the connective nerve with the homologous $S$ cells of the anterior and posterior ganglia, forming a fast conducting circuit linking all ganglia in the CNS (Muller and Scott, 1981). However, the S cell expresses a unique innexin, Hve-inx6 (Dykes and Macagno, 2006), not found in the APs. Could the innexin composition of the innexons assembled by a cell help determine whether the homologous neurons retract interacting branches? It may also be important to consider that, although there are other motor neurons that display axonal homolog avoidance behaviors similar to the AP (Gao and Macagno, 1987a,b), there are also many other homologous neurons, particularly sensory neurons in leech ganglia, that extend axons up and 
down the interganglionic connective nerves but do not form any GJs, permanent or transient, between their processes.

The AP-AP GJ permeability is different from those of most of the other well studied electrical synapses in the leech CNS and hence may allow a different set of signaling molecules to be exchanged. While allowing the passage of 5-HT (MW 212; Wolszon et al., 1994b, 1995; M. W. Baker and E. R. Macagno, unpublished observations), the AP-AP GJ does not allow the passage of Neurobiotin (MW 322), which can readily cross between most of the nonrectifying synapses that have been characterized in the leech (Fan et al., 2005; Firme et al., 2012). Furthermore, our results confirm that Hve-inxl is necessary for signaling AP neuron homolog avoidance, but Hve-inxl is a pan-neuronally expressed innexin, so it is unlikely that it is sufficient for mediating the signal exchanged by AP homologs. For example, the adult AP neuron expresses three other innexin genes (Kandarian et al., 2012), which will each need to be tested for having any role(s) in homolog avoidance.

Another interesting question raised by these results is why none of the experimental AP neurons that extended their connective axons after INX1-GJ perturbation did not also sprout projections out of the ipsilateral ganglionic nerve roots. Previous studies have revealed that homolog avoidance can occur not only between extrasegmental AP neurons but also between contralateral AP neurons from the same ganglion. Killing one of the AP neurons during a critical window, from E15 to E25, leads to sprouting by the contralateral homolog out of the ipsilateral nerve roots such that the remaining AP neuron now has projections out of each side of the ganglion (Wolszon et al., 1995). Could this represent a different type of homolog avoidance? One possible explanation might be that the INX1based GJs responsible for the avoidance response of the connective axon are different from the INX1-based GJs found in the ganglion itself.

\section{What is the AP-AP GJ signal in the connective?}

What might be the nature of the soluble signal exchanged by the AP s projections? The symmetry of the interaction appears to create a paradoxical situation because, whatever the signal is, it does not act as a self-inhibiting factor on its source cell at the same time that it inhibits the homolog. Because the homologous axons do not immediately stop extending when they meet and form GJs but rather continue growing until they have formed a significant region of overlap (Fig. 2 B, C; Wolszon et al., 1994b), it is possible that the shafts act as sinks for a soluble growth factor, mutually reducing its concentration in the growth cones to below a level at which it can be effective, thus stopping growth. Other mechanisms are possible, of course, and the issue may only be resolved when the actual signal has been identified.

One possible GJ signal would be $\mathrm{Ca}^{2+}$. Fura-2 imaging of the ganglionic connective during the period when the AP axons overlap has demonstrated that $\mathrm{Ca}^{2+}$ waves generated in one of the AP cells travel across the AP-AP connective GJs and into the axon of the extrasegmental AP (Wolszon et al., 1994a). It is also worth considering that GJ proteins have increasingly been shown to have a much wider spectrum of physiological functions than just permitting intercellular passage of soluble molecules. For example, $\mathrm{Ca}^{2+}$ release leading to $\mathrm{Ca}_{2}{ }^{+}$wave propagation in cultured cells and ATP release by erythrocytes requires connexons and or pannexons channels (Cotrina et al., 1998; Bao et al., 2004; Locovei et al., 2006). In the leech ganglion, a glial innexin, Hve-inx2 (Dykes et al., 2004; Dykes and Macagno,
2006), can function as a nonjunctional mechanosensitive innexon, releasing ATP into the extracellular space in response to nerve injury (Bao et al., 2007; Samuels et al., 2010). The adhesive properties of some of the connexins, including their roles in cellular migration, are thought to involve coreceptor signaling and cytoskeletal remodeling (Matsuuchi and Naus, 2013). These effects depend on the ability of the extracellular loops to dock with apposing connexons (Elias et al., 2007, 2010), and the presence of the $C$ tail of $\mathrm{cx} 43$, which can bind directly with tubulin (Giepmans et al., 2001). A role for downstream transcriptional control in $\mathrm{AP}-\mathrm{AP}$ homolog avoidance can also not be excluded. Among olfactory neurons in Caenorhabditis elegans, GJ signaling has been shown to repress transcriptional factors controlling gene expression and cellular fate (Chuang et al., 2007; Hsieh et al., 2012).

Several important distinctions can be made between the homolog avoidance described between the connective axons of the $\mathrm{AP}$ and neuronal dendritic tiling among sensory cells. Perhaps foremost, one occurs between the axons of homologous cells, and the other describes an interaction that occurs principally between their dendrites. In fact, the body wall innervation of the AP is known to overlap considerably with the extrasegmental homologs (Gan and Macagno, 1997). Unlike certain sensory cells, for which a non-overlapping arbor can provide sensory discrimination, the AP neuron is believed to function as a motor efferent, helping to modulate sensory neuron activity. Second, although dendritic tiling between sensory cells is thought to occur on a rapid timescale (minutes) with dynamic filopodial extensions followed by rapid retraction on contacting a neighboring or isocellular process (Wang and Macagno, 1997; Sugimura et al., 2003; Baker and Macagno, 2007), AP homolog avoidance in the connective occurs over several days (Wolszon et al., 1994b). Indeed, in view of this fact and in light of the S-cell response described above, we had hypothesized that the initial interaction in the connective between the AP axons, and like that of the S-cell axons, is one of adhesion so that, although the AP axon many initially continue to extend, over time as more inter-axonal plaques are formed, this extension stops. However, unlike with the $S$ cells, whose connection is presumed to be INX6 based and whose axons also overlap considerably in the connective (McGlade-McCulloh and Muller, 1989), the INX1-based channel in the AP axon conduct a unique symmetrical signal affecting the axons of both cells so that eventually they retract, collapsing back to the ganglion. Another possibility might have been that INX6 GJ adhesion is significantly stronger than that of INX1, leading the S-cell axons to remain attached in the connective but not those of the APs. However, our results with the S2 cellular aggregation assays revealed that INX1 and INX6 innexons display comparable adhesive affinities (Fig. 7). Together, these findings support the view that intercellular communication and not cellular adhesion underlies AP neuron homolog avoidance.

In summary, our results confirm the role of GJs as critical mediators of axonal homolog avoidance. In the future, imaging the AP connective axons using fluorescent reporter indicators may help illuminate the second-messenger signal(s) responsible for this cellular behavior.

\section{References}

Ambrosi C, Boassa D, Pranskevich J, Smock A, Oshima A, Xu J, Nicholson BJ, Sosinsky GE (2010) Analysis of four connexin26 mutant gap junctions and hemichannels reveals variations in hexamer stability. Biophys J 98: 1809-1819. CrossRef Medline 
Baker MW, Macagno ER (2000) RNAi knockdown of the receptor tyrosine phosphatase HmLAR2 in a single cell of an intact embryo leads to growth cone collapse. Curr Biol 10:1071-1074. CrossRef Medline

Baker MW, Macagno ER (2006) Characterizations of Hirudo medicinalis DNA promoters for targeted gene expression. J Neurosci Methods 156: 145-153. CrossRef Medline

Baker MW, Macagno ER (2007) In vivo imaging of growth cone and filopodial dynamics: evidence for contact-mediated retraction of filopodia leading to the tiling of sibling processes. J Comp Neurol 500:850-862. CrossRef Medline

Baker MW, Peterson SM, Macagno ER (2008) The receptor phosphatase HmLAR2 collaborated with focal adhesion proteins in filopodial tips to control growth cone morphology. Dev Biol 320:215-225. CrossRef Medline

Bao L, Locovei S, Dahl G (2004) Pannexin membrane channels are mechanosensitive conduits for ATP. FEBS Lett 572:65-68. CrossRef Medline

Bao L, Samuels S, Locovei S, Macagno ER, Muller KJ, Dahl G (2007) Innexins form two types of channels. FEBS Lett 581:5703-5708. CrossRef Medline

Beahm DL, Oshima A, Gaietta GM, Hand GM, Smock AE, Zucker SN, Toloue MM, Chandrasekhar A, Nicholson BJ, Sosinsky GE (2006) Mutation of a conserved threonine in the third transmembrane helix of alpha- and beta-connexins creates a dominant-negative closed gap junction channel. J Biol Chem 281:7994-8009. CrossRef Medline

Blackshaw SE, Nicholls JG, Parnas I (1982) Expanded receptive fields of cutaneous mechanoreceptor cells after single neurone deletion in leech central nervous system. J Physiol 326:261-268. Medline

Cheng A, Tang H, Cai J, Zhu M, Zhang X, Rao M, Mattson MP (2004) Gap junctional communication is required to maintain mouse cortical neural progenitor cells in a proliferative state. Dev Biol 272:203-216. CrossRef Medline

Chuang CF, Vanhoven MK, Fetter RD, Verselis VK, Bargmann CI (2007) An innexin-dependent cell network establishes left-right neuronal asymmetry in C. elegans. Cell 129:787-799. CrossRef Medline

Cotrina ML, Lin JH, Alves-Rodrigues A, Liu S, Li J, Azmi-Ghadimi H, Kang J, Naus CC, Nedergaard M (1998) Connexins regulate calcium signaling by controlling ATP release. Proc Natl Acad Sci U S A 95:15735-15740. CrossRef Medline

Cusato K, Bosco A, Rozental R, Guimarães CA, Reese BE, Linden R, Spray DC (2003) Gap junctions mediate bystander cell death in developing retina. J Neurosci 23:6413-6422. Medline

Depriest A, Phelan P, Martha Skerrett I (2011) Tryptophan scanning mutagenesis of the first transmembrane domain of the innexin ShakingB(Lethal). Biophys J 101:2408-2416. CrossRef Medline

Dykes IM, Macagno ER (2006) Molecular characterization and embryonic expression of innexins in the leech Hirudo medicinalis. Dev Genes Evol 216:185-197. CrossRef Medline

Dykes IM, Freeman FM, Bacon JP, Davies JA (2004) Molecular basis of gap junctional communication in the CNS of the leech Hirudo medicinalis. J Neurosci 24:886-894. CrossRef Medline

Elias LA, Wang DD, Kriegstein AR (2007) Gap junction adhesion is necessary for radial migration in the neocortex. Nature 448:901-907. CrossRef Medline

Elias LA, Turmaine M, Parnavelas JG, Kriegstein AR (2010) Connexin 43 mediates the tangential to radial migratory switch in ventrally derived cortical interneurons. J Neurosci 30:7072-7077. CrossRef Medline

Fan RJ, Marin-Burgin A, French KA, Otto Friesen W (2005) A dye mixture (Neurobiotin and Alexa 488) reveals extensive dye-coupling among neurons in leeches; physiology confirms the connections. J Comp Physiol A Neuroethol Sens Neural Behav Physiol 191:1157-1171. CrossRef Medline

Fernández J, Stent GS (1982) Embryonic development of the hirudinid leech Hirudo medicinalis, structure, development and segmentation of the germinal plate. J Embryol Exp Morphol 72:71-96. Medline

Firme CP 3rd, Natan RG, Yazdani N, Macagno ER, Baker MW (2012) Ectopic expression of select innexins in individual central neurons couples them to pre-existing neuronal or glial networks that express the same innexin. J Neurosci 32:14265-14270. CrossRef Medline

Gan WB, Macagno ER (1995) Interactions between segmental homologs and between isoneuronal branches guide the formation of sensory terminal fields. J Neurosci 15:3243-3253. Medline

Gan WB, Macagno ER (1997) Competition among the axonal projections of an identified neuron contributes to the retraction of some of those projections. J Neurosci 17:4293-4301. Medline
Gao WQ, Macagno ER (1987a) Extension and retraction of axonal projections by some developing neurons in the leech depends upon the existence of neighboring homologues. I. The HA cells. J Neurobiol 18:43-59. CrossRef Medline

Gao WQ, Macagno ER (1987b) Extension and retraction of axonal projections by some developing neurons in the leech depends upon the existence of neighboring homologues. II. The AP and AE neurons. J Neurobiol 118:295-313. Medline

Gao WQ, Macagno ER (1988) Axon extension and retraction by leech neurons: severing early projections to peripheral targets prevents normal retraction of other projections. Neuron 1:269-277. CrossRef Medline

Giepmans BN, Verlaan I, Hengeveld T, Janssen H, Calafat J, Falk MM, Moolenaar WH (2001) Gap junction protein connexin-43 interacts directly with microtubules. Curr Biol 11:1364-1368. CrossRef Medline

Goodman CS, Spitzer NC (1979) Embryonic development of identified neurones: differentiation from neuroblast to neurone. Nature 280:208-214. Medline

Grueber WB, Jan LY, Jan YN (2002) Tiling of the Drosophila epidermis by multidendritic sensory neurons. Development 129:2867-2878. Medline

Haley B, Hendrix D, Trang V, Levine M (2008) A simplified miRNA-based gene silencing method for Drosophila melanogaster. Dev Biol 321:482490. CrossRef Medline

Hsieh YW, Chang C, Chuang CF (2012) The microRNA mir-71 inhibits calcium signaling by targeting the TIR-1/Sarm 1 adaptor protein to control stochastic L/R neuronal asymmetry in C. elegans. PLoS Genet 8:e1002864. CrossRef Medline

Huckfeldt RM, Schubert T, Morgan JL, Godinho L, Di Cristo G, Huang ZJ, Wong RO (2009) Transient neurites of retinal horizontal cells exhibit columnar tiling via homotypic interactions. Nat Neurosci 12:35-43. CrossRef Medline

Juven-Gershon T, Cheng S, Kadonaga JT (2006) Rational design of a super core promoter that enhances gene expression. Nat Methods 3:917-922. CrossRef Medline

Kandarian B, Sethi J, Wu A, Baker MW, Yazdani N, Kym E, Sanchez A, Edsall L, Gaasterland T, Macagno ER (2012) The medicinal leech genome encodes 21 innexin genes: different combinations are expressed by identified central neurons. Dev Genes Evol 222:29-44. CrossRef Medline

Kramer AP, Kuwada JY (1983) Formation of the receptive fields of leech mechanosensory neurons during embryonic development. J Neurosci 3:2474-2486. Medline

Kramer AP, Stent GS (1985) Developmental arborization of sensory neurons in the leech Haementeria ghilianii. II. Experimentally induced variations in the branching pattern. J Neurosci 5:768-775. Medline

Lefebvre JL, Kostadinov D, Chen WV, Maniatis T, Sanes JR (2012) Protocadherins mediate dendritic self-avoidance in the mammalian nervous system. Nature 488:517-521. CrossRef Medline

Locovei S, Bao L, Dahl G (2006) Pannexin 1 in erythrocytes: function without a gap. Proc Natl Acad Sci U S A 103:7655-7659. CrossRef Medline

Long H, Ou Y, Rao Y, van Meyel DJ (2009) Dendrite branching and selfavoidance are controlled by Turtle, a con- served IgSF protein in Drosophila. Development 136:3475-3484. CrossRef Medline

Lopresti V, Macagno ER, Levinthal C (1974) Structure and development of neuronal connections in isogenic organisms: transient gap junctions between growing optic axons and lamina neuroblasts. Proc Natl Acad Sci U S A 71:1098-1102. CrossRef Medline

Matsuuchi L, Naus CC (2013) Gap junction proteins on the move: connexins, the cytoskeleton and migration. Biochim Biophys Acta 1828:94-108. CrossRef Medline

McGlade-McCulloh E, Muller KJ (1989) Developing axons continue to grow at their tip after synapsing with their appropriate target. Neuron 2:1063-1068. CrossRef Medline

Melinek R, Muller KJ (1996) Action potential initiation site depends on neuronal excitation. J Neurosci 16:2585-2591. Medline

Millard SS, Flanagan JJ, Pappu KS, Wu W, Zipursky SL (2007) Dscam2 mediates axonal tiling in the Drosophila visual system. Nature 447:720 724. CrossRef Medline

Muller KJ, Scott SA (1981) Transmission at a "direct" electrical connection mediated by an interneurone in the leech. J Physiol 311:565-583. Medline

Nardelli-Haefliger D, Shankland M (1993) Lox10, a member of the NK-2 homeobox gene class, is expressed in a segmental pattern in the endoderm and in the cephalic nervous system of the leech Helobdella. Development 118: 877-892. Medline 
Perry VH, Linden R (1982) Evidence for dendritic competition in the developing retina. Nature 297:683-685. CrossRef Medline

Phelan P (2005) Innexins: members of an evolutionarily conserved family of gap-junction proteins. Biochim Biophys Acta 1711:225-245. CrossRef Medline

Qiu L, Wang H, Xia X, Zhou H, Xu Z (2008) A construct with fluorescent indicators for conditional expression of miRNA. BMC Biotechnol 8:77. CrossRef Medline

Ri Y, Ballesteros JA, Abrams CK, Oh S, Verselis VK, Weinstein H, Bargiello TA (1999) The role of a conserved proline residue in mediating conformational changes associated with voltage gating of $\mathrm{Cx} 32$ gap junctions. Biophys J 76:2887-2898. CrossRef Medline

Sambrook J, Fritsch EF, Maniatis T (1989) Molecular cloning: a laboratory manual, 2nd edition. Cold Spring Harbor, NY: Cold Spring Harbor Laboratory.

Samuels SE, Lipitz JB, Dahl G, Muller KJ (2010) Neuroglial ATP release through innexin channels controls microglial cell movement to a nerve injury. J Gen Physiol 136:425-442. CrossRef Medline

Stegmeier F, Hu G, Rickles RJ, Hannon GJ, Elledge SJ (2005) A lentiviral microRNA-based system for single-copy polymerase II-regulated RNA interference in mammalian cells. Proc Natl Acad Sci U S A 102:1321213217. CrossRef Medline

Suchyna TM, Xu LX, Gao F, Fourtner CR, Nicholson BJ (1993) Identification of a proline residue as a transduction element involved in voltage gating of gap junctions. Nature 1365:847-849. Medline

Sugimura K, Yamamoto M, Niwa R, Satoh D, Goto S, Taniguchi M, Hayashi S, Uemura T (2003) Distinct developmental modes and lesion-induced reactions of dendrites of two classes of Drosophila sensory neurons. J Neurosci 23:3752-3760. Medline
Taghert PH, Bastiani MJ, Ho RK, Goodman CS (1982) Guidance of pioneer growth cones: filopodial contacts and coupling revealed with an antibody to Lucifer Yellow. Dev Biol 94:391-399. CrossRef Medline

Todd KL, Kristan WB Jr, French KA (2010) Gap junction expression is required for normal chemical synapse formation. J Neurosci 30:1527715285. CrossRef Medline

Wang H, Macagno ER (1997) The establishment of peripheral sensory arbors in the leech: in vivo time-lapse studies reveal a highly dynamic process. J Neurosci 17:2408-2419. Medline

Wang H, Macagno ER (1998) A detached branch stops being recognized as self by other branches of a neuron. J Neurobiol 35:53-64. CrossRef Medline

Wolszon LR, Rehder V, Kater SB, Macagno ER (1994a) Calcium wavefronts that cross gap-junctions may signal neuronal death during development. J Neurosci 14:3437-3448. Medline

Wolszon LR, Gao WQ, Passani MB, Macagno ER (1994b) Growth cone "collapse" in vivo: are inhibitory interactions mediated by gap junctions? J Neurosci 14:999-1010. Medline

Wolszon LR, Passani MB, Macagno ER (1995) Interactions during a critical period inhibit bilateral projections in embryonic neurons. J Neurosci 15:1506-1515. Medline

Yazdani N, Firme CP 3rd, Macagno ER, Baker MW (2013) Expression of a dominant negative mutant innexin in identified neurons and glial cells reveals selective interactions among gap junctional proteins. Dev Neurobiol 73:571-586. CrossRef Medline

Zipursky SL, Grueber WB (2013) The molecular basis of self-avoidance. Annu Rev Neurosci 36:547-568. CrossRef Medline 